\title{
EVALUATION OF CRESTAL BONE LOSS IN CONVENTIONAL AND COMPUTER GUIDED MANDIBULAR IMPLANT OVERDENTURES
}

\author{
Eman Mostafa Ahmed Ibraheem*, Wafa'a R Al-Magaleh**, \\ Ahmed E El-Sisy* and Mohamed A Abdel Aal***
}

\begin{abstract}
Purpose: The present study was conducted to evaluate bone height changes around implants installed with conventional \& computer guided stent implant placement in implant overdentures.

Material and Methods: Twelve completely edentulous patients were selected had received two implants in inter-foramina areas. They were divided into two groups. Group (I): a conventional surgical stent was used. However; in Group (II) a computer guided surgical stent was used for implant placement. For both Groups, Mandibular overdentures were constructed retained by Locator attachments. Crestal bone loss was assessed with the aid of CBCT at time of denture insertion, 3 , 6 , and 12 months later. The data were collected and presented as mean values of bone height loss. The data were then statistically analyzed.
\end{abstract}

Results: The results revealed that there was no statistically significant difference between the two studied groups at the first 6-months after implant function. However, after 12 months the bone loss was significantly lower in Group (II) than Group (I).

Conclusion: Within the limitations of the present study it may be concluded that: The use of computer guided implant installation may induce less crestal bone resorption than conventionally placed implants.

KEYWORDS: Implant overdentures, Computer guided, locator attachment, Crestal bone loss

\section{INTRODUCTION}

Accurate implant placement is a pre-requisite for long term success of dental implants and implant supported prostheses as well. Biomechanical, esthetics and maintenance considerations require accurate implant placement. Improperly aligned dental implants may result in early \& or delayed implant failures. ${ }^{(1)}$
For accurate implant placement; several techniques were presented during the clinical settings. Ridge palpation, ridge mapping, diagnostic casts' evaluation, osteometer, conventional surgical stents, as well as the use of simple radiographs are the most commonly used methods besides the recent techniques ${ }^{(2,3)}$

\footnotetext{
* Researcher in Fixed and Removable Prosthodontic Department, National Research Centre, Cairo, Egypt ** Assistant Professor, Prosthodontic Department, Faculty of Oral and Dental Medicine, Sana'a University, Yemen *** Lecturer of Prosthodontics, Faculty of Oral and Dental Medicine, Beni-Suef University
} 
Three-dimensional visualization of the dental hard tissues is recently provided via the use of Cone Beam Computerizes tomography (CBCT). ${ }^{(4)}$

CBCT measurements may be more accurate than CT measurements in the assessment of implant site dimensions accrording to the current literature. ${ }^{(5)}$

Surgical planning software and CBCT are utilized nowadays to produce CAD/CAM surgical templates allowing 3-D evaluation of future implant positions. These new developments have contributed to the popularization of flapless approach which can be performed with greater levels of confidence. There are many planning software for template- guided surgery are now available. ${ }^{(6)}$

Flapless implant placement has been considered by surgeons for immediate implants to the preserve the vascular supply and existing soft tissue contours. Flapless implant placement may induce less bleeding, less swelling, less discomfort for the patient, shorter surgery time, decreased healing time and post-operative pain. ${ }^{(7,8)}$

Flapless implant surgery may be contra-indicated advisable in cases with absent labial or buccal bone, reduced width of alveolar ridge, or a need for alveoloplasty to create prosthetic space. ${ }^{(9)}$

Perforation of the buccal or lingual bony plate perforation of the buccal or lingual bone plates are intra-operative complications of flapless surgery. ${ }^{(10)}$

Moreover, implants primary stability at the time of implant placement may be compromised, leading to submerging implants in given situations. ${ }^{(11,12)}$

Computer guided implant installation in edentulous arches was recently evaluated in many studies. The installed implants in these studies had shown encouraging results and high implant survival rates when used in adequately selected cases. $(13,14,15)$

\section{MATERIALS AND METHODS}

Twelve completely edentulous male patients were enrolled in this study.

All patients were informed about the research strategy \& had signed a written informed consent form to be enrolled in the present study.

CBCT was made for all patients to evaluate bone quantity \&quality in the mandibular canine region.

Conventional Complete dentures were constructed prior to surgical intervention.

The mandibular dentures were duplicated into clear acrylic resin to be utilized as a radiographic stent for all patients.

\section{Patients were divided into two Groups}

\section{Group (I)}

- The radiographic stent was modified to be used as a conventional surgical stent for implant placement.

- The surgical stent was hollowed in the area of mandibular canines from the lingual side while the buccal wall was left intact.

- The surgical stent was tried- in the patient mouth, adjusted till surgical implant installation. Fig.(1)

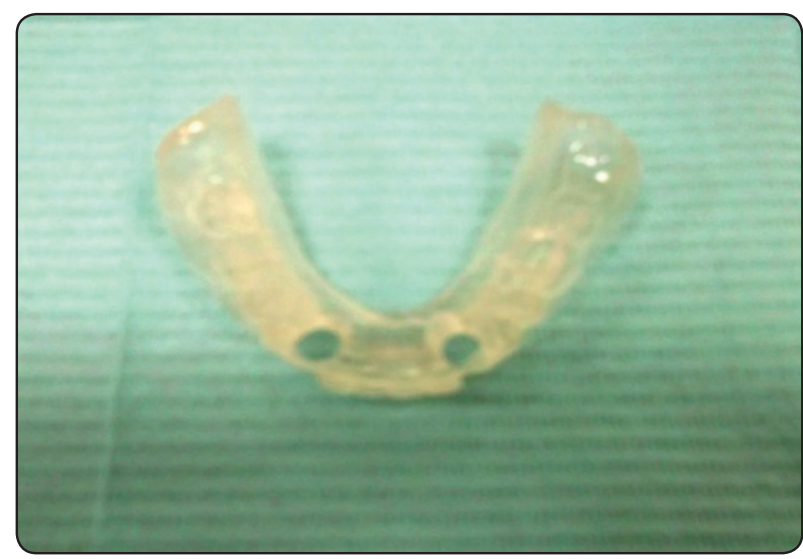

Fig. (1) Clear acrylic resin conventional surgical stent 


\section{Group (II)}

- The mouth opening for this Group was evaluated as reduced mouth opening may jeopardize positioning of the surgical instruments with computer assisted surgical stent ${ }^{(16)}$

Construction of the computer guided stent:

- Gutta-percha markers were inserted into the radiographic stent in six cylindrical channels which were cut \&distributed at the facial and lingual sides of the ridge anterior and posterior on both sides.

- CBCT scan was performed in two phases.

- The First scan was made while the patient wearing the radiographic stent.

- Patients were instructed to stabilize the radiographic stent by biting on two cotton rolls during CBCT scan to allow jaw separation.

- In the second scan, the radiographic guide was separately scanned.

- The scanning data of the patient $\&$ that of the radiographic guide were matched with the aid of the Gutta - percha markers.
- Data were transferred to the milling center to fabricate the surgical template by the rapid prototyping technique (3-D Printing technique).

- Surgical planning was made by the clinician on a computer screen for correct implant placement with respect to position and angulations in a virtual three dimensional view. Fig. (2)

- $2 \mathrm{~mm}$ guide tubes were incorporated in the surgical template to direct the placement of the implants during surgery in the same position as had been virtually planned. Fig.(3)

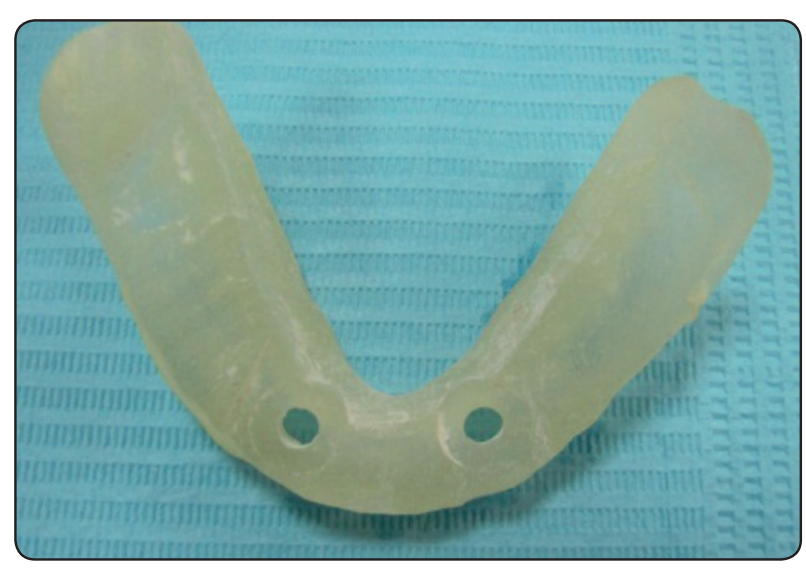

Fig.(3) Computer guided surgical stent
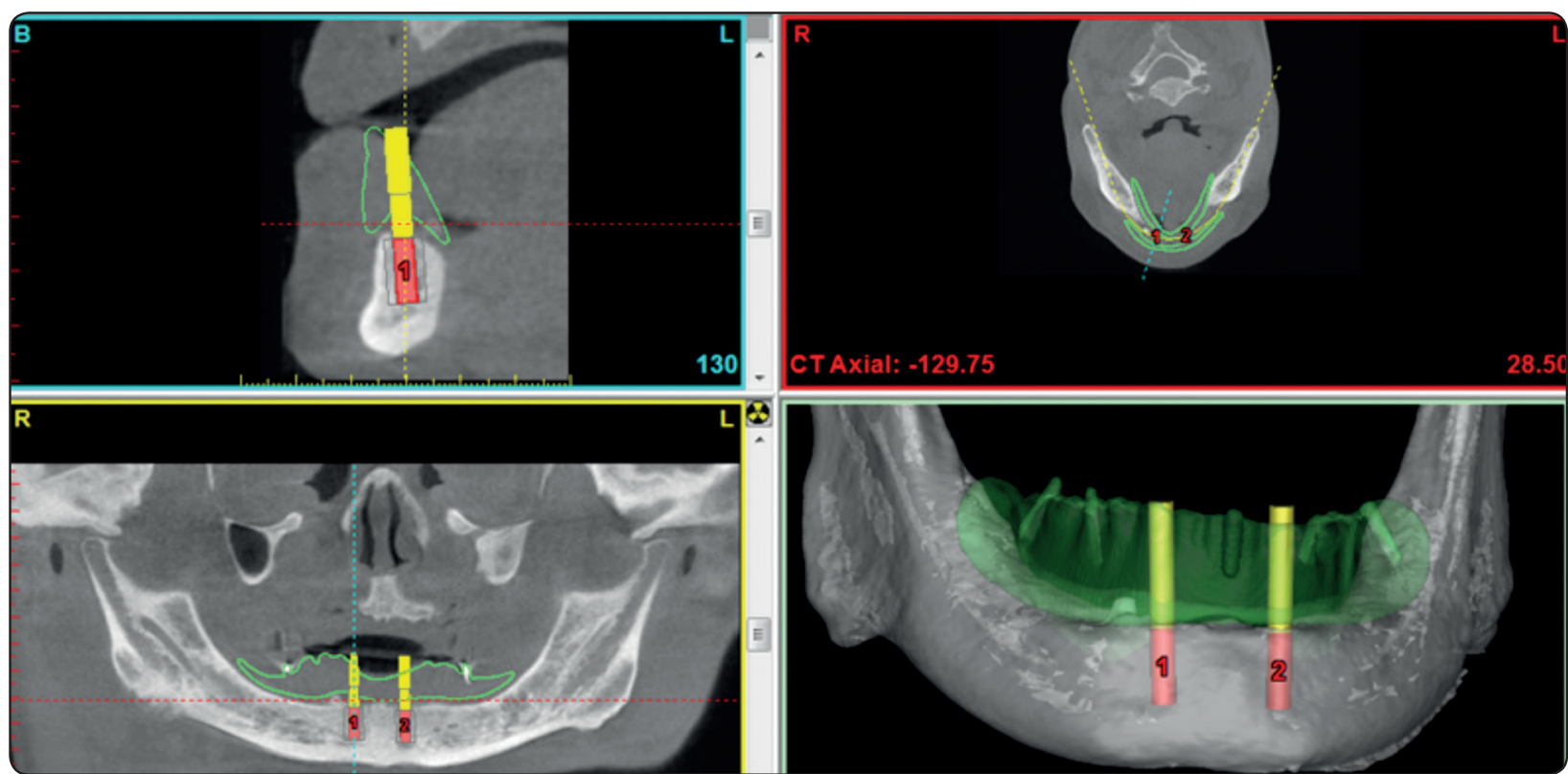

Fig. (2) Virual implant placement by Sim/Plant program 


\section{Pre-surgical instructions}

- Patients were motivated to gain \& maintain good oral hygiene for professional oral hygiene measures prior surgery.

- Patients were instructed to rinse with a chlorhexidine mouthwash $0.2 \%$ for 1 minute, twice a day, and two days prior to surgical intervention and thereafter for 2 weeks.

- They had received prophylactic antibiotic therapy: Amoxicillin 2 gm 1 hour prior surgery.

- Two Tapered Legacy Implants (Zimmer Dental, Carlsbad, CA, USA) with diameters of $3.7 * 13$ and $11.5 \mathrm{~mm}$ were selected.

\section{SURGICAL PROTOCOL}

- For both groups implants were installed in the inter-foraminal region with the aid of the surgical stents.

- In Group (I): Conventional mucoperiosteal flap was elevated at the areas of lower canines bilaterally leaving the area between them intact.

- In Group (II): Mucosa covering the proposed implant bed was removed using $3.5 \mathrm{~mm}$ tissue punch to gain access to the alveolar bone.

- The long drills were utilized to prepare the implant osteotomy sites in Group (II) , However, convention drills were utilized in group (I).

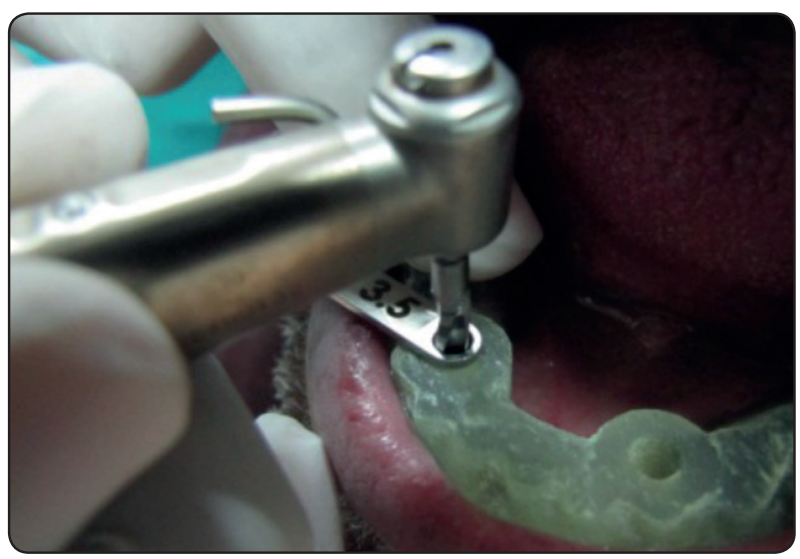

Fig.(4) Drilling with the aid of Computer guided surgical stent
- Implants were installed in the osteotomy sites with a torque $40 \mathrm{~N} / \mathrm{cm}$ for both groups. Fig. (4)

- Implants were left buried for 3-4 months till complete osseointegration.

\section{Post -surgical instructions:}

- Patients were instructed to avoid brushing and trauma at the surgical site till suture removal.

- Cold and soft diet was recommended for 7 days after surgery.

- The dentures were adjusted, relined with a soft lining material (Rite-line Rite, Dent. Mfg. Corp, USA) and immediately delivered to the patients.

- Patients were recalled every two weeks for oral hygiene maintenance, prosthetic check-ups.

- After verifying osseointgeration with the aid of CBCT; implants were uncovered to receive locator attachments.

\section{Prosthetic Adjustments}

- Locator attachments were attached to implants after un-covering. Fig.(5)

- The dentures were prepared by removal of acrylic resin opposite to the implants sites.

- Functional fitting of dentures was made upon the locator attachments.

- Occlusal adjustments were made for overdentures

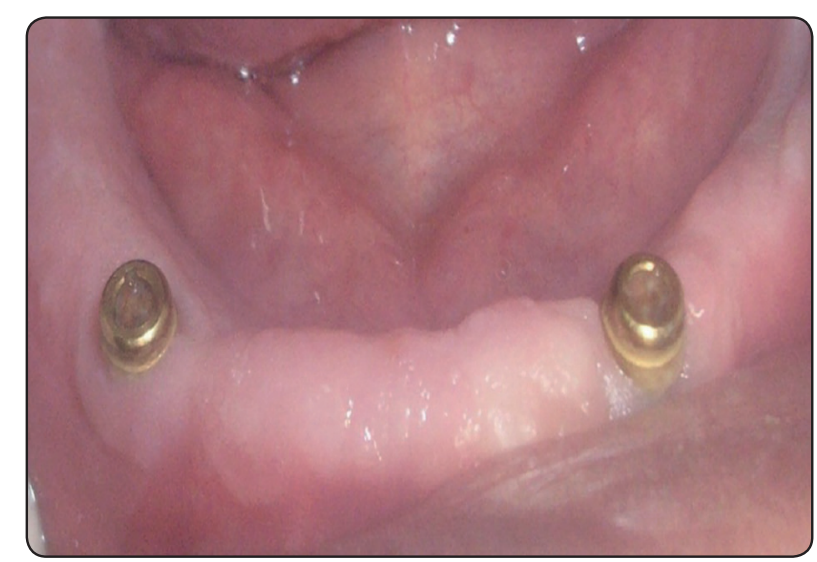

Fig. (5) Locator attachments attached to implants 


\section{Radiographic Assessment}

- Peri-implant Marginal bone loss were assessed with CBCT radiographs after 3, 6\& 12 months after overdenture loading for both groups.

\section{Bone height measurements}

- Mesial \& distal crestal bone levels were measured from the reconstructed corrected sagittal views by drawing a line parallel to the implant serrations extending from the crestal bone to the apical end of the implant.

- Similarly, buccal and lingual bone levels were measured from the cross-sectional views.

- Average readings of the four sides at each interval were calculated and tabulated for statistical analysis. Fig.(6)

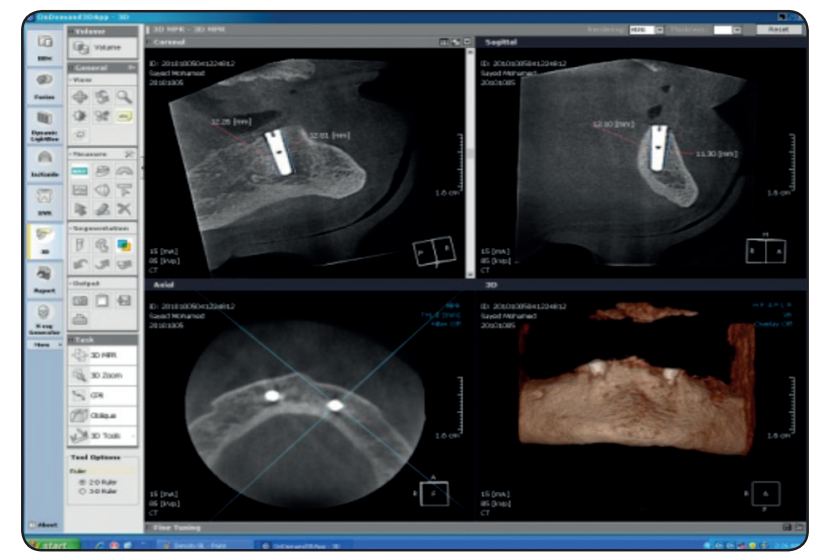

Fig. (6) Assessment of crestal bone height changes by CBCT.

\section{RESULTS}

The results of the present study revealed a decrease in bone height along follow up period; Different capital letters indicate significant difference between the two studied groups at the same follow-up interval according to t-test.

On the other hand; different small letters indicates significant difference between the followup periods according to repeated measurement one-way analysis of variance and Bonferroni t-test for pairwise comparison. *: significant at $\mathrm{P}<0.05$; $\mathrm{P}>0.05$ (non-significant), $\mathrm{P}<0.05$ (significant), and $\mathrm{P}<0.01$ (highly significant

The results shown in Table (I) \& Fig. (7) reported that the mean marginal bone loss for both groups increased significantly along the follow-up period (p <0.001).

After 3-months of loading, the mean marginal bone loss for conventional and flapless surgery group were 0.08 and $0.099 \mathrm{~mm}$. However, after 6 months of loading the mean marginal bone loss for conventional and flapless group were 0.36 and $0.32 \mathrm{~mm}$.

On comparing the two studied groups, there was no statistically significant difference between them in marginal bone loss during the first and second follow-up intervals $\mathrm{P}=0.164$ and $\mathrm{P}=0.496$ respectively.

However, after one year the mean values of crestal bone loss for Group (I) \& Group (II) were 0.85 and 0.6 with statistically significant difference. $(\mathrm{P}=0.009)^{*}$

TABLE (I) Comparison of marginal bone loss (mm) between group (I) \& group (II) follow-up period

\begin{tabular}{|c|c|c|c|c|c|}
\cline { 2 - 5 } \multicolumn{1}{c|}{} & $\begin{array}{c}\text { After 3 months } \\
(0-3 \mathrm{~m})\end{array}$ & $\begin{array}{c}\text { After 6months } \\
(0-6 \mathrm{~m})\end{array}$ & $\begin{array}{c}\text { After 1 year } \\
(0-12 \mathrm{~m})\end{array}$ & F-value & $\mathrm{p}$-value \\
\hline $\begin{array}{c}\text { Conventional implant } \\
\text { placement }\end{array}$ & $0.080 \pm 0.0882^{\mathrm{aA}}$ & $0.360 \pm 0.067^{\mathrm{bA}}$ & $0.851 \pm 0.130^{\mathrm{cA}}$ & 124.861 & $<0.001^{*}$ \\
\hline Computer guided implant & $0.151 \pm 0.099^{\mathrm{aA}}$ & $0.323 \pm 0.132^{\mathrm{aA}}$ & $0.606 \pm 0.177^{\mathrm{bB}}$ & 18.828 & $<0.001^{*}$ \\
\hline t-value & 1.473 & -0.700 & -3.090 & \multicolumn{2}{|c}{} \\
\cline { 1 - 4 } & $\mathrm{P}=0.164$ & $\mathrm{P}=0.496$ & $\mathrm{P}=0.009^{*}$ & \multicolumn{2}{|c}{}
\end{tabular}




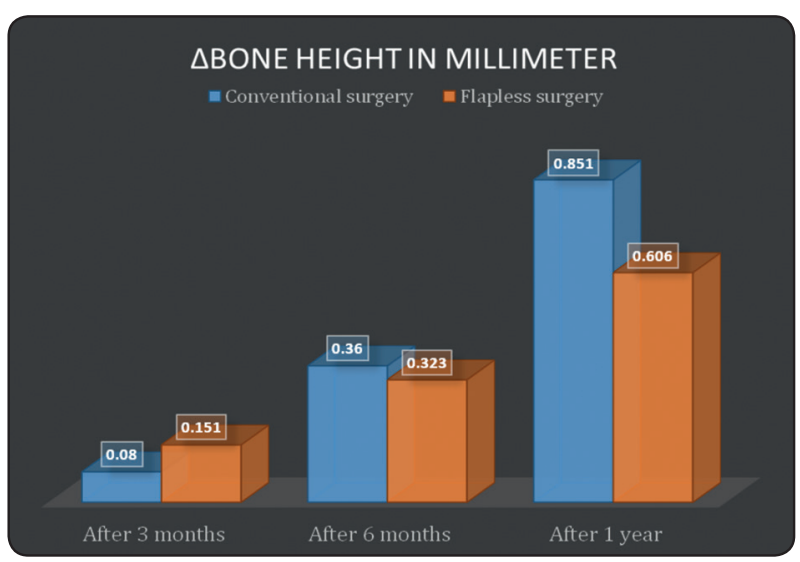

Fig. (7) Bone height changes for conventional \& computer guided implant placement along the follow-up.

\section{DISCUSSION}

All patients participated in the present study were satisfied with their implant overdentures. ${ }^{(17,18)}$

This may be attributed to the improved retention of the mandibular over dentures after locator attachment. The high retention of Locator attachments may be attributed to the combination of external and internal retentive mating surfaces, a concept known as "dual retention", which creates more than twice the retentive surface area of other attachments. This excellent retention had the patients with sense of security, allowing better life style $^{(18,19)}$

Crestal bone resorption around implants is a well-known phenomenon occurring mostly as an immediate bone response after implant insertion as well as after functional implant loading. ${ }^{(20)}$

The amount of bone resorption occurring after loading may be related to many factors as the amount of load, nature of prosthesis, bone quantity and quality, implant related factors (design, number and dimensions), opposing restoration and crown height space. ${ }^{(20,21)}$

In the present study, conventional \&computer assisted surgical stents were utilized for implant installation.
There was a gradual increase in bone loss in both groups along the study period. This finding may agree with previous studies which had reported that bone resorption occurs within the first year after implants loading with an average of $1.2 \mathrm{~mm}$ and it does not contradict with implant success. ${ }^{(22) .}$

On comparing bone height loss in both groups the results revealed that there was a significant decreased amount of bone loss in Group (II) after one year. This finding may be due to the accurate treatment planning for implant installation with the aid of the computer guided surgical stent. ${ }^{(21-24)}$

This Computer assisted implant installation allowed proper implant angulations' in their beds, leading to better load distribution along the long axis of implant . ${ }^{(25,26)}$

This proper positioning may also minimize the off-set forces which are detrimental to the bone surrounding the implant. Consequently, this might explain the significant reduced bone height loss compared to the conventionally place implants.

Moreover, flapless implant placement in group (II) may preserve blood supply \& reduce the surgical trauma leading to reduced bone resorption after one year of function. ${ }^{(25,26)}$.

\section{REFERENCES}

1. Worthington P, Rubenstein J, Hatcher DC: The role of cone-beam computed tomography in the planning and placement of implants. J Am Dent Assoc, 2010;141 (3): 19-24

2. Fortin T, Bosson J, Coudert JL, Isidori M.: Reliability of preoperative planning of an image guided system for oral implant placement based on 3D images: An In vivo study. INT J Oral Maxillofac Implants, 2003;18 :886-893

3. Lee, C. K.; Agar, J. R.: Surgical and prosthetic planning for a two-implant-retained mandibular overdenture: a clinical report. The Journal of prosthetic dentistry 2006, 95, 102-5.

4. Kopp KC, Koslow AH, Abdo OS. (2003).: Predictable implant placement with diagnostic surgical template and advanced radiographic imaging. J Prosthet Dent 2003; 89(6): 611-17 
5. Monsour PA, Dudhia R.: Implant radiography and radiology. Aust Dent J, 2008; 53: 11-25

6. Al-Ekrish, A.A and Ekram, M. A . Comparative study of the accuracy and reliability of multi-detector computed tomography and cone beam computed tomography in the assessment of dental implant site dimension. Dentomaxillofac Radiol, 2011;40: 67-75.

7. Fortin T, Bosson JL, Isidori M, Blanchet E.: Effect of flapless surgery on pain experienced in implant placement using an image-guided system. Int. J Oral Maxillofac. Implants 2006; 21:29.

8. Ludlow JB, Laster WS, See M, Bailey LJ, Hershey HG. Accuracy of measurements of mandibular anatomy in cone beam computed tomography images. Oral Surg Oral Med Oral Pathol Oral Radiol Endod, 2007;103:534-42

9. Brodala N. Flapless surgery and its effect on dental implant outcomes. Int J Oral Maxillofac Implants 2009; 24:118-125.

10. Bidra AS. Consequences of insufficient treatment planning for flapless implant surgery for a mandibular overdentures: a clinical report. J.Prosthet Dent 2011,105 (5): 286-91.

11. Campelo LD, Camara JR. Flapless implant surgery: A 10year clinical retrospective analysis. Int J Oral Maxillofac Implants 2002;17:271-276

12. Wittwer G,Adeyemo WL, Schicho K, Figl M, Enislidis G. Navigated Flapless transmucosal implant placement in the mandible: A pilot study in 20 patients. Int J Oral Maxillofac Implants 2007; 22: 801-807.

13. Malo P, de Araujo Nobre M, Lopes A. The use of computer guided flapless implant surgery and four implants placed in immediate function to support a fixed denture: Preliminary results after a mean follow-up period of thirteen months. J Prosthet Dent 2007;97(6):26-34.

14. Sanna AM, Molly L, van Steenberghe D. Immediately loaded CAD-CAM manufactured fixed complete dentures using flapless implant placement procedures: A cohort study of consecutive patients. J Prosthet Dent 2007; 97: 331-339.

15. Van Steenberghe D, Glauser R, Blomback U, et al. A computed tomographic scan-derived customized surgical template and fixed prosthesis for flapless surgery and immediate loading of implants in fully edentulous maxillae: A prospective multicenter study. Clin Implant Dent Relat Res 2005; 7( 1): 111-120.
16. Valente F, Schiroli G, Sbrenna A. Accuracy of computeraided oral implant surgery: a clinical and radiographic study. Int J Oral Maxillofac Implants 2009;24:234 Y242

17. Feine, J. S.; Carlsson, G. E.; Awad, M. A.; Chehade, A.; Duncan, W. J.; Gizani, S.; et al.,.: The McGill consensus statement on overdentures. Mandibular two-implant overdentures as first choice standard of care for edentulous patients. Montreal, Quebec, May 24-25, 2002. The International journal of oral \& maxillofacial implants 2002, 17, 601-2.

18. Meijer HJ, Raghoebar GM, Van't Hof MA. Patient satisfaction with mandibular implant overdentures and conventional dentures: a 10-year prospective study of clinical aspects and patient satisfaction. INT J Oral Maxillofac Impl 2003; 18:879-85.

19. Alsabeeha NH, Payne AG, Swain MV. Attachment systems for mandibular two-implant overdentures: a Review of in-vitro investigations on retention and wear features. Int J Prosthodont 2009; 22:429-40.

20. Chung, D. M.; Oh, T. J.; Lee, J.; Misch, C. E.; Wang, H. L.: Factors affecting late implant bone loss: a retrospective analysis. The International journal of oral \& maxillofacial implants 2007, 22, 117-26.

21. Danza, M.; Tortora, P.; Quaranta,A.; Perrotti, V.; Vozza, I.; Piattelli, A.: Randomised study for the 1-year crestal bone maintenance around modified diameter implants with different loading protocols: a radiographic evaluation. Clinical oral investigations 2010, 14, 417-26.

22. Misch,C.E.: Contemporary Implant Dentistry; ${ }^{3 r d}$ ed.; CV Mosby Co.: St. Louis, 2008.

23. Jeong SM, Choi BH, Kim J, Xuan F, Lee DH, Mo DY, Lee CU. A 1-year prospective clinical study of soft tissue conditions and marginal bone changes around dental implants after flapless implant surgery. Oral Surg Oral Pathol Oral Radiol Endod. 2011; 111(1): 41-6

24. Balshi SF, Wolfinger GJ, Balshi TJ. Guided implant placement and immediate prosthesis delivery using traditional Branemark system abutments: a pilot study of 23 patients. Implant Dent 2008;17: 128-135.

25. Becker W, Goldstein M, Becker BE, Sennerby L, Kois D, Hujoel P. Minimally invasive flapless implant placement: follow-up results from multicenter study.J Periodontol. 2009 Feb; 80(2):347-52.

26. Holst S, Blatz MB, Eitner S. Precision for computer-guided implant placement: using 3D planning software and fixed intraoral reference points. J Oral Maxillofac Surg 2007;65:393-9. 